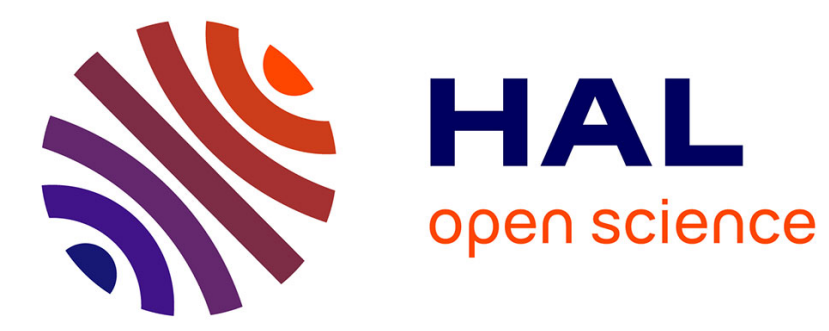

\title{
Characterization of promoter elements required for cardiac chamber-specific expression
}

\author{
T. Majalahti, H. Tokola, H. Ruskoaho, O. Vuolteenaho
}

\section{To cite this version:}

T. Majalahti, H. Tokola, H. Ruskoaho, O. Vuolteenaho. Characterization of promoter elements required for cardiac chamber-specific expression. Molecular and Cellular Endocrinology, 2009, 307 (1-2), pp.50. 10.1016/j.mce.2009.03.013 . hal-00521549

\section{HAL Id: hal-00521549 \\ https://hal.science/hal-00521549}

Submitted on 28 Sep 2010

HAL is a multi-disciplinary open access archive for the deposit and dissemination of scientific research documents, whether they are published or not. The documents may come from teaching and research institutions in France or abroad, or from public or private research centers.
L'archive ouverte pluridisciplinaire HAL, est destinée au dépôt et à la diffusion de documents scientifiques de niveau recherche, publiés ou non, émanant des établissements d'enseignement et de recherche français ou étrangers, des laboratoires publics ou privés. 


\section{Accepted Manuscript}

Title: Characterization of promoter elements required for cardiac chamber-specific expression

Authors: T. Majalahti, H. Tokola, H. Ruskoaho, O.

Vuolteenaho

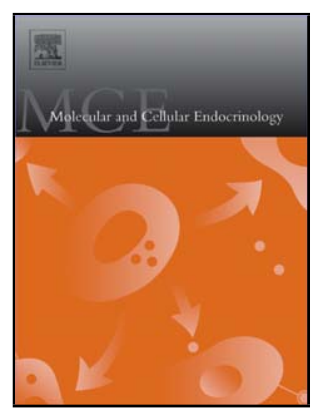

PII:

S0303-7207(09)00174-9

DOI: doi:10.1016/j.mce.2009.03.013

Reference: MCE 7172

To appear in: Molecular and Cellular Endocrinology

Received date: 5-8-2008

Revised date: 21-1-2009

Accepted date: 5-3-2009

Please cite this article as: Majalahti, T., Tokola, H., Ruskoaho, H., Vuolteenaho, O., Characterization of promoter elements required for cardiac chamber-specific expression, Molecular and Cellular Endocrinology (2008), doi:10.1016/j.mce.2009.03.013

This is a PDF file of an unedited manuscript that has been accepted for publication. As a service to our customers we are providing this early version of the manuscript. The manuscript will undergo copyediting, typesetting, and review of the resulting proof before it is published in its final form. Please note that during the production process errors may be discovered which could affect the content, and all legal disclaimers that apply to the journal pertain. 


\section{Characterization of promoter elements required for cardiac chamber-} specific expression

Majalahti $\mathrm{T}^{1}$, Tokola $\mathrm{H}^{2}$, Ruskoaho $\mathrm{H}^{2}$ and Vuolteenaho $\mathrm{O}^{1}$

Departments of Physiology ${ }^{l}$ and Pharmacology and Toxicology ${ }^{2}$, Institute of Biomedicine, Biocenter Oulu, University of Oulu, Oulu, Finland; FIN-90014

Correspondence/Reprint requests to:

Olli Vuolteenaho, MD, PhD, Professor of Physiology

Department of Physiology, Faculty of Medicine, University of Oulu P.O. Box 5000, FIN-90014 University of Oulu, Finland tel.: 358-8-5375302, fax: 358-8-5375320, e-mail: olli.vuolteenaho@oulu.fi

Key words: cardiac-specific, gene expression, hybrid promoters, natriuretic peptides 


\begin{abstract}
Salmon cardiac natriuretic peptide (sCP, an A-type natriuretic peptide) is an excellent model for the study of cardiac chamber-specific gene expression because it is uniquely specific to the heart and its promoter drives gene expression effectively in mammalian cardiac atrial but not in ventricular cells. We have now prepared hybrid luciferase constructs containing specific sequences from both $\mathrm{sCP}$ and BNP 5' promoters. According to our results the simple addition of a short rat BNP proximal promoter fragment to the inert 846 nucleotide sCP proximal promoter increases 100 times the basal activity of the sCP promoter in rat ventricular cardiomyocytes, and also conveys inducibility by mechanical load and endothelin-1. Thus, a small rBNP promoter fragment can transform the prototypical A-type natriuretic peptide regulation of sCP to B-type regulation, a result which argues against a major role of repressors causing the low expression level of A-type peptides in ventricular cardiomyocytes.
\end{abstract}




\section{Introduction}

The mechanism of cardiac-specific gene expression has been under intensive study. A number of genetic elements and transcription factors have been found guiding the gene expression to the heart, or more specifically, to the cardiac atria or ventricles (Tabibiazar et al., 2003; Barth et al., 2005). Overall it has been found by microarray studies that $23 \%$ of cardiac genes show differences in gene expreession between the atria and ventricles (Tabibiazar et al., 2003). Myocyte enhancer factor-2 (MEF-2) regulates the ventricle-specific expression of the mouse myosin light chain $2 \mathrm{v}$ gene (Ross et al., 1996). GATA-4 has an important regulatory function in the atrial-specific expression of myosin light chain $2 \mathrm{a}$ (MLC2a), slow myosin heavy chain 3 (MHC3) and atrial natriuretic peptide (ANP) genes (McBride and Nemer, 2001; Temsah and Nemer 2005). Nkx-2.5 interacts with GATA-4 in the repression of ventricular expression of the ANP gene (Durocher et al., 1996; Durocher and Nemer, 1998; Small and Krieg, 2003) while serum response factor (SRF) is an important positive regulator of the atrial expression of both ANP and MLC2a (Small and Krieg, 2004).

In this study, we have used the 5' promoter of salmon cardiac peptide (sCP) (Tervonen et al., 1998; Majalahti-Palviainen et al., 2000) as a model for examining the mechanisms of chamber-specificity of cardiac gene expression. $\mathrm{sCP}$ has two features which makes it especially suitable for the present purpose: i) its expression is uniquely specific to the heart, ii) the $5^{\prime}$ promoter of $\mathrm{sCP}$ gene is highly active when transfected to mammalian atrial cells but shows only marginal activity in ventricular cells (Majalahti-Palviainen et al., 2000). On the other hand, we and others have extensive experience with the characterization of the promoter of rat B-type natriuretic peptide (BNP), a cardiac peptide, which is expressed in both atria and ventricles, and to a lesser degree in other tissues as well (Gerbes et al., 1994). Our aim was to examine whether defined promoter elements can be used to transfer the characteristical chamber-specific expression profiles between the promoters of sCP and rat $\mathrm{BNP}$.

We were especially interested in finding out the reason for the inefficacy of the sCP promoter in ventricular cells, as the same promoter clearly fulfills the requirements for heartspecificity and high activity in atrial cells. We have prepared hybrid luciferase constructs containing specific sequences from both $\mathrm{sCP}$ and $\mathrm{BNP} 5$ ' promoters and used them to characterize the chamber-specific regulation of gene expression in basal conditions as well as under stimulation by ET-1 and mechanical loading in rat neonatal cardiac cell cultures. For 
comparison, we have also tested the ventricular expression of the $\mathrm{sCP}$ promoter by $\underline{\text { in vivo }}$ model in rats.

\section{Materials and methods}

\subsection{Animals}

Neonatal, 2- to 4-day old Sprague-Dawley rats of both sexes (I, III) and male 2-month old SD rats (270-300 g, II), obtained from the center for Experimental Animals at the University of Oulu, Finland, were used. The experimental designs were approved by the Animal care and use Committee of the University of Oulu, Finland.

\subsection{Luciferase reporter gene constructs}

The gene constructs were made by subcloning parts of the sCP and rat BNP gene 5'flanking sequences in pGL3 Basic (Promega Corp.) vector upstream of the firefly (Photinus pyralis) luciferase reporter gene. The -1686 sCPluc and -534 rBNPluc have been described earlier (Majalahti-Palviainen et al., 2000; Pikkarainen et al., 2002). The -846/-134rBNP luc ( 46 nucleotides nearest of +1 in the $-846 \mathrm{sCP}$ promoter replaced by the $-134 \mathrm{rBNP}$ promoter fragment from rat BNP gene) was obtained by PCR using the $-1686 \mathrm{sCPluc}$ as template for the sCP part (PCR primers: 5' GTCATTATGGCCTCTC plus $\underline{K n} \mathbf{I}$ linker; 3' ACGCCATACACACACACACACATACAGAGG plus $\underline{E c o}$ R1 linker) and the -534 rBNPluc as a template for the BNP part (PCR primers: 5' GGGTGAATTCTCAGGTCCTG including $\underline{E c o R} 1$ restriction site; 3' CACTAGCCTCTCAGCAACGGTG plus $\underline{B a m} \mathrm{H} 1$ linker). The -846/-46sCP was first subloned into the pBluescript $\mathrm{SK}^{+}$vector (pBS) and the plasmid was then opened with $\underline{E c o} \mathrm{R} 1$ and $\underline{B a m} \mathrm{H} 1$ and the $-134(+4) \mathrm{rBNP}$ fragment was subcloned between the sCP and the pBS. Then the whole sCP/BNP insert was cut by $\underline{K n} \mathrm{I}$ and $\underline{B a m} \mathrm{H} 1$ and subcloned into pGL3 Basic vector digested with $\underline{K p n I}$ and $\underline{B g} / \mathrm{III}$. The respective $\mathrm{SCP} / \mathrm{BNP}$ construct with mutated GATA -80/-91 was obtained by the same way, except that the template for the BNP part was the -534rBNPGATAmutluc described earlier (Pikkarainen et al., 2003b). The -96 sCPluc was obtained by PCR by using the -1686 sCPluc as a template (PCR primers: 5'CCACTGACACCAGACCGTCT plus $\underline{K n} \underline{I}$ linker; 3' GATTCCATTTAGGCTGCGG plus $\underline{B a m} \mathrm{H} 1$ linker), and by subcloning the PCR product into 
pGL3 Basic vector. The BNPGATA/sCPluc was obtained by annealing BNP oligonucleotide 5'CCAGGAATGTGTCTGATAAATCAGAGATAACGGTACC with its antisense oligonucleotide (with $\underline{K p n} \mathrm{I}$ overhangs) and by subcloning the BNP oligo to the $\underline{K p n} \mathrm{I}$ digested -96sCPluc (the BNPGATA at the 5' site of the -96sCP). The BNPEBS/sCPluc was obtained by annealing BNP oligonucleotide 5'CAGCTACCAGAGTGCCCGGAAGTGGTGCAGC GGTACC with its antisense oligonucleotide (with $\underline{K p n} \mathrm{I}$ overhangs) and by subcloning the BNP oligo to the $\underline{K n} \mathrm{I}$ digested -96sCPluc (the BNPEBS at the 5'site of the $-96 \mathrm{sCPluc}$ ). The respective GATA and EBS mutated $\mathrm{BNP} /-96 \mathrm{sCP}$ constructs were obtained by the same manner by using BNP oligonucleotides with mutated -80/-91 GATA; 5' CCAGGAATG TGTCTTGCAAATCAGATGCAACGGTACC (mutated nucleotides in bold) and with mutated -496 EBS; 5' CAGCTACCAGAGTGCCCAGCCTCCGTGCAGCGGTACC (mutated nucleotides in bold). The deletion construct sCPgapluc was obtained by PCR using the $-1686 \mathrm{sCP}$ luc as a template (PCR primers 5'ATCATTACTGATAA; $3{ }^{\prime}$ ATGTGAATTA TCTGT with $\underline{K p n} \mathrm{I}$ linkers), and by subloning the $-1426 /-957$ sCP insert to $\underline{K p n} \mathrm{I}$ digested 96sCPluc. All the gene constructs were sequenced for verification.

\subsection{Cell culture and transient transfections}

Three-day-old Sprague-Dawley rats were killed by cervical dislocation, and the ventricles were dissected (Majalahti-Palviainen et al., 2000). The myocytes were dispersed by collagenase digestion and gentle trituration by repeated aspiration into a Pasteur pipette. Cells were washed twice with DMEM-Ham's F-12 nutrient mix (Biochrom) and preincubated for $30 \mathrm{~min}$ to remove most of the contaminating fibroblasts. Cells were plated in 24-well plates with 0.5 million cells/well. They were grown in DMEM-Ham's F-12 supplemented with 10\% FBS, 1.28\% L-glutamine, and 1\% (100 IU) penicillin-streptomycin.

The transfections were made $18 \mathrm{~h}$ after plating by introducing $0.5 \mathrm{ug}$ gene construct with $1.5 \mu \mathrm{g}$ Fugene transfection reagent per 0.5 million cells according to the manufacturers instructions (Roche Molecular Biochemicals). All of the gene constructs were cotransfected with the thymidine kinase renilla luciferase vector $(0.5 \mu \mathrm{g}$, Promega Corp. $)$ to control the transfection efficiency. The transfection was allowed to continue for 6 hours in DMEMHam's F-12/10 \% FBS, after which it was stopped by removing the medium.

The cells were rinsed twice with DMEM-Hams F-12, and complete serum-free medium $(1.15 \%$ insulin-transferrin-sodium-selenite, $1.28 \%$ L-glutamine, $1 \%$ penicillin- 
streptomycin, $1 \mathrm{nmol} /$ liter $\mathrm{T}_{3}, 2.8 \mathrm{nmol} /$ liter sodium pyruvate and $0.25 \% \mathrm{BSA}$ in DMEMHam's F-12) was added.

The medium was replaced daily, and the cells were harvested $48 \mathrm{~h}$ posttransfection. The cells were washed twice with PBS and lysed in reporter lysis buffer (Promega Corp.). The luciferase activities of the samples were measured with a Luminoskan RS luminometer (Labsystems, Helsinki, Finland).

\subsection{Endothelin-1 and mechanical stretch experiments}

Endothelin-1 (10 nM, Sigma) was introduced to the medium 24 hours after the transfection and the cells were harvested 24 hours later (Pikkarainen et al., 2003a). Cyclic mechanical stretch was introduced to attached myocytes after $24 \mathrm{~h}$ in serum-free medium by applying a computer-controlled vacuum suction under the flexible-bottomed Bioflex collagen plates with Flexercell Strain Unit FX-3000 (Flexcell). The vacuum varied in two-second cycles at a level sufficient to promote $10-25 \%$ elongation of the cardiomyocytes at the point of maximal distension of the culture surface (Pikkarainen et al., 2003b).

\subsection{Nuclear protein extraction and electrophoretic mobility shift assays}

Nuclear protein extractions and gel mobility shift assay method used for the detection of sequence-specific DNA-binding proteins have been described earlier (Hautala et al., 2001). The specificity of the transcription factor binding was confirmed by competition with unlabeled oligonucleotides with intact or mutated binding sites as well as by supershift experiments using specific antibodies (Santa Cruz Biotechnology) against GATA-4 (cat \#sc1237-X), GATA-5 (sc-7280-X), GATA-6 (sc-7244-X), the members of activator protein-1 (AP-1) complex (c-Fos (sc-52-X), c-Jun (sc-45-X), JunB (sc-46-X), JunD (sc-74-X)), Etslike gene-1 (p-Elk-1) (sc-840-X), Nkx-2.5 (sc-8697) and Oct-1 (sc-25399).

\subsection{In vivo injections, Ang II infusion and reporter gene assays}

Rats were anesthetized with an intraperitoneal injection of $250 \mu \mathrm{g} / \mathrm{kg}(160 \mu \mathrm{mol} / \mathrm{kg})$ medetomidine hydrochloride and $50 \mathrm{mg} / \mathrm{kg}(182 \mu \mathrm{mol} / \mathrm{kg})$ ketamine hydrochloride. Plasmids (in $100 \mu \mathrm{l}$ of $0.9 \% \mathrm{NaCl}$ ) were injected directly into the left ventricular wall close to the apex 
(Kass-Eisler and Leinwand 1997; Marttila et al., 2001; Majalahti et al., 2007). The plasmid DNA consisted of $50 \mu \mathrm{g}$ of construct DNA as well as $100 \mu \mathrm{g}$ of $\beta$-galactosidase expression vector (pSV $\beta$-gal, Promega Co). Ang II $33.3 \mu \mathrm{g} / \mathrm{kg} / \mathrm{h}(31.5 \mathrm{nmol} / \mathrm{kg} / \mathrm{h})$ or $0.9 \% \mathrm{NaCl}$ as vehicle were administered by SC minipumps for 2 weeks in conscious rats as previously described (Suo et al., 2002; Majalahti et al., 2007). The administration of Ang II was started simultaneously with the plasmid injections. Reporter gene activities of the left ventricles were measured by using luciferase and $\beta$-galactosidase assays with Luminoskan RS luminometer. Luciferase values were divided by $\beta$-galactosidase values to correct for variation in transfection efficiency (Marttila et al., 2001; Majalahti et al., 2007) .

\subsection{Statistical analysis}

The results are expressed as mean $\pm \mathrm{SD}$. Analysis of variance followed by Bonferroni's test was used for comparison between the groups (GraphPad InStat for Mac OS X, GraphPad Software). A value of $P<0.05$ was considered statistically significant.

\section{Results}

\subsection{Activation of $S C P$ promoter by replacing the proximal promoter area by $B N P$}

While sCP 5' promoter is highly active in neonatal rat atrial cells it is nearly inert in ventricular cells. The inefficacy can be due to lack or misplacement of critical elements in the SCP promoter, or it could be caused by the presence of repressor action. While the sCP gene 5'-promoter shares potential elements with that of BNP gene, such as GATA and AP-1 consensus binding sites, they are located much more distally with respect to the transcription start site $(+1)$ compared with BNP gene. Therefore, the low activity of sCP promoter in ventricular cells could be simply due to the suboptimal location of the binding elements. To test this hypothesis we first prepared a hybrid luciferase construct in which the 46 nucleotides upstream the transcription start site $(+1)$ of the $-846 \mathrm{sCP}$ luc is replaced by the $-134 \mathrm{rBNP}$ promoter fragment from rat BNP gene (Fig. 1). This simple modification transformed the inactive sCP promoter to very active in ventricular cells (Fig. 2A), a result which appears to make unlikely the presence of important repressor mechanisms. The hybrid promoter 
construct was approximately 100 times more active than the native sCP promoter. It is also noteworthy that the highly active hybrid construct contained (at -118 to -124 and -170 to -176 bp) two intact NKE consensus binding sites, an element believed to serve as a recognition sequence for a repressor complex that inhibits ANP expression in ventricular cardiomyocytes (Durocher et al. 1996; Habets et al. 2002).

\subsection{GATA motif is important in the proximal BNP promoter}

A prominent feature of - $134 \mathrm{rBNP}$ is the presence of GATA binding sites at positions 80 and -91 . They have been shown to be crucial for BNP gene expression in the heart. To find out whether these sites are responsible for the activation of $\mathrm{sCP}$ promoter we prepared a hybrid sCP/-134rBNP luciferase construct, in which the GATA sites have been mutated incapable to bind GATA transcription factors (Fig. 1). The double GATA mutation markedly decreased the activation in ventricular cells (by $\approx 40 \%$, Fig. $2 \mathrm{~A}$ ). Thus, the the GATA sites clearly are important, but still account for less that $50 \%$ of the activating effect, indicating the presence of other major regulatory elements in the $-134 \mathrm{rBNP}$ promoter fragment.

\subsection{Placing the GATA-, CArG-and AP-1 -rich sequences closer to the transcription start site does not activate the $\mathrm{SCP}$ promoter in ventricular cardiomyocytes}

According to our results it would therefore seem that the promoter activity requires that the crucial binding elements are situated in close proximity of the transcription start site. To examine whether this itself is sufficient for high promoter activity in ventricular cells we prepared a further luciferase construct that harbors nucleotides -1426/-957 of sCP 5'promoter linked to a minimal sCP promoter (-96sCPluc), thus placing the GATA-, CArG and AP-1 -rich sequences in SCP promoter close to the transcription start site, within comparable distances as they are in mammalian natriuretic peptide promoters (Fig. 1). When transfected to neonatal rat ventricular cells the construct did not show any higher activity than the native -1686sCPluc promoter construct (Fig. 2B). In fact, the activity appeared to be even lower, although it should be recognized that both are only minimally active $(<1 \%)$ when compared to the $-534 \mathrm{rBNP}$ promoter (Fig. 2B). Thus the inefficacy of the native sCP promoter in ventricular cardiomyocytes appears not to be explainable by the non-proximity of the key binding elements. 


\subsection{GATA-4 binds to the $S C P$ promoter}

Several GATA and other consensus binding sites, typical for natriuretic peptide promoters, can be found in the 5' flanking sequence of sCP gene (Majalahti-Palviainen et al., 2000). To find out whether they actually bind to transcription factors we performed electrophoretic mobility shift and supershift assays with nuclear extracts from neonatal rat ventricular myocytes. We tested the following potential binding sites: GATA(-) (-148 bp upstream from transcription start site), NKElike (-118 and -170), MEF2 (-605), AP-1 (-878), and GATA (-1417). Of these only GATA (-1417) resulted in a supershift with the appropriate antibody. Specific GATA 4 antibody caused the supershift, whereas antibodies against GATA 5 or 6 did not nor did the unspecific Octamer-1 (Oct-1) antibody (Fig. 3).

\subsection{Small GATA and EBS BNP fragments inserted to the 5 'site of the $S C P$ promoter enhance} the basal activity

Thus the straightforward insertion of the proximal promoter of rBNP gene can change the otherwise inactive sCP promoter to one with high basal activity in rat ventricular cardiomyocytes. The GATA sites have been shown to be important for BNP gene induction by mechanical stretching and the EBS site for induction by endothelin-1 (Pikkarainen et al., 2003a; 2003b). On the other hand we have previously shown that sCP gene expression does not respond to either of these stimuli (Kokkonen et al., 2000). We have also tried to activate sCPluc gene constructs in neonatal rat ventricular cells by a number of hypertrophic factors including ET-1, but the sCP promoter has been inert (unpublished results).

To find out whether the inducibility of rat BNP gene can be transferred from rat BNP gene with small defined promoter fragments, we used the luciferase constructs described above and prepared further constructs in which oligonucleotides containing the BNP GATA 91/-80 sites or the Ets-binding site (EBS -495) from rBNP gene resided upstream from the inert proximal -96 sCPluc promoter fragment. When transfected to neonatal rat ventricular cells the addition of either element markedly enhanced the basal activity of -96 sCPluc promoter, although only to $\approx 20 \%$ of the level achieved with the insertion of $-134 \mathrm{rBNP}$. Mutation of the GATA or EBS consensus sites decreased or abolished the activating effect (Fig. 4). 


\subsection{BNP inserts in the $\mathrm{SCP}$ promoter bring inducibility by mechanical stretch of the cardiomyocytes}

We examined the effect of mechanical load by cyclic stretching of neonatal rat ventricular cells in culture $(10-25 \%, 0.5 \mathrm{~Hz}, 24$ hours) using a Flexercell apparatus. The activities of the constructs after transfection and stretching were compared to non-stretched controls. The $-846 \mathrm{sCP} /-134 \mathrm{rBNP}$ hybrid construct was induced by the cyclic mechanical stretch stimulus $(\mathrm{P}<0.05)$, and there was a tendency for induction with BNP GATA/96sCPluc and BNP EBS/-96sCPluc hybrid constructs (Fig. 5). The effect was modest in all cases. The control vector pGL3control as well as the minimal -96 sCPluc construct and the sCPluc gap deletion construct in which the endogenous GATA, AP-1 and CarG elements were moved close to the transcription start site, did not show any induction.

\subsection{Proximal BNP promoter in the $S C P / B N P$ construct responds to ET-1 stimulation}

To find out whether the responsiveness to endothelin-1 can be transferred from rat BNP gene to sCP gene, the neonatal rat ventricular cells were transfected with the promoter constructs, let to grow for $24 \mathrm{~h}$ and then treated with $10 \mathrm{nM}$ ET-1 for further $24 \mathrm{~h}$. The luciferase activities were compared with the control transfection samples treated with vehicle (Fig. 6). The $-846 \mathrm{sCP} /-134 \mathrm{rBNPluc}$ promoter with the BNP sequence located 3 ' to that of sCP was induced significantly by ET-1. Mutating the GATA site did not affect on the inducibility of this construct. Surprisingly, the EBS/-96sCPluc construct was not induced significantly with ET-1 (Fig.6).

\subsection{The sCP promoter shows some ventricular activity in vivo, but is not induced by Ang II}

In addition to in vitro analysis of the sCP promoter activity, we have studied the most active promoter construct, $-1686 \mathrm{sCPluc}$, activity in vivo in adult rat cardiac ventricles with or without Ang II infusion. We injected the plasmid construct directly in the left ventricular wall after which the rats were infused with vehicle or Ang II for 2 weeks. In the control group, we injected the -534 rBNPluc previously shown to possess high activity and Ang II inducibility (Majalahti et al., 2007). The -1686sCP drove luciferase expression more effectively in cardiac ventricular tissue than in isolated ventricular cells, but its activity level was still 
$\approx 15 \%$ of the -534 rBNPluc activity. The sCP promoter activity was not affected by Ang II (Fig. 7).

\section{Discussion}

Salmon cardiac peptide (sCP) belongs to the family of A-type natriuretic peptides on the basis of its expression profile as well as functional properties (Kokkonen et al., 2000; Majalahti-Palviainen et al., 2000; Tervonen et al., 1998; 2000; 2001; 2002; Vierimaa et al., 2002; 2006). Low expression level in the ventricles during the adult period, which can be induced by chronic overload, is typical for the A-type natriuretic peptides (Ruskoaho, 1992; McGrath et al., 2005). This is a sign of the reappearance of fetal pattern of cardiomyocyte gene expression associated with ventricular overload, hypertrophy and dysfunction (Lorell \& Carabello, 2000). Horsthuis et al. (2008) have recently reported that elements required for fetal pattern and for hypertrophy-associated active ventricular ANP expression are located distally in the 5' promoter, 11-141 kbp upstream from the transcription start site. However, we found in the present study that the 5 ' promoter fragment of sCP which is practically silent in rat ventricular cells ("ANP-type") and devoid of these distant sequences, can be transformed to a promoter active in both atrial and ventricular cardiomyocytes ("BNPtype"), simply by adding a short proximal promoter fragment from rat BNP, another natriuretic peptide. The promoter fragment $-134 \mathrm{rBNP}$ from rat BNP gene introduced between the $-846 /-46 \mathrm{sCP}$ promoter fragment and the luciferase reporter gene caused enormous activation in rat ventricular cardiomyocytes. Point mutation of -80/-91 GATA sites previously shown to bind GATA-4 (Pikkarainen et al., 2004) decreased the activation by approximately $40 \%$, showing that the GATA sites are important but not sole elements involved. These results strongly suggest that the low activity of sCP promoter in ventricular cells, as compared to atrial cells, is not due to repressor action. Instead it appears to be due to lack of proximal binding elements in the native sCP 5' promoter required for efficient transcription in ventricular cardiomyocytes. If generally applicable as a model of A-type natriuretic peptides, our results would indicate that the switch to the fetal pattern of ventricular cardiomyocyte gene expression may not be due to release from the action of specific repressors or the action of specific activators but rather due to a general differentiation of ventricular cardiomyocytes towards the atrial type. Thus it would appear that ANP gene expression is restricted to atrial-type cardiomyocytes. 
Our results with the hybrid promoter constructs provided a rather complex picture about the importance of the location of the specific binding elements in the promoter sequence. We could show that the elements transferred from the rat BNP proximal promoter activate the sCP promoter, but much more effectively if they are located downstream with respect to the $\mathrm{sCP}$ elements. On the other hand, placing the native sCP GATA, AP-1 and CarG elements closer to the transcription start site (sCPluc gap deletion construct harboring nucleotides -1426/-957 linked to a $-96 \mathrm{sCP}$ minimal promoter), as they are in the $\mathrm{BNP}$ promoter, was not sufficient to activate the $\mathrm{SCP}$ promoter in neonatal rat ventricular cardiomyocytes. This indicates that the non-proximity of the sCP binding elements is not the primary reason for the inefficacy of the native $\mathrm{SCP}$ promoter in ventricular cells.

The proximal GATA sites at $-80 /-91$ of rat BNP promoter have been shown to be important not only for the basal activity of the BNP promoter, but also for its induction by various stimuli, such as mechanical stretch (Pikkarainen et al., 2003b). GATA-4 regulates in cooperation with Nkx-2.5 BNP the promoter induction by mechanical stretch in ventricular myocytes (Pikkarainen et al., 2003b). We have recently shown that GATA-4 binding to the proximal GATA sites is essential in the activation of BNP gene expression by angiotensin II induced hypertension in vivo (Majalahti et al., 2007). On the other hand GATA factors appear not to have a major role in endothelin-1-induced BNP promoter activation (Pikkarainen et al., 2002), whereas BNP EBS and pElk-1 (phosphorylated Elk-1) are important (Pikkarainen et al., 2003a).

In this study, the addition of the proximal -134 rBNP fragment to the sCP promoter brought inducibility by ET-1 and mechanical stretch in ventricular cardiomyocytes. Similarly, an even simpler modification, insertion of the BNP GATA oligonucleotide to the sCP promoter carried inducibility by stretch. The failure of EBS/-96sCPluc to respond to endothelin-1 may be surprising. However, the oligonucleotide-based EBS/-96sCPluc construct has a very simple structure compared to the native contructs used in our previous studies. ETS-factors are required for the activation of transcription by endothelin-1 (Pikkarainen et al., 2003a) but they may not be sufficient for it. The present results results indicate that the endothelin response is more complex and probably requires additional binding elements.

sCP proximal promoter contains a consensus two consensus NKE binding sites at 118 to -124 bp and -170 to -176 bp upstream from transcription initiation (Majalahti et al., 2000). These sequences, 5'-TGAAGTG-3' and 5'-TTAAGTG-3', respectively, meet the criteria of high affinity $n k x-2.5$ binding sites (Chen and Schwartz, 1995). NKE has been 
implicated to play a major role in the regulation of chamber-specific expression of ANP. It seems that although a number of regulatory elements are essential for efficient expression of ANP in the myocardium in general, chamber-specific expression is mediated through binding sites for NKx-2.5 and GATA-4 (the NKE and GATA sites, respectively). Mutation of either the NKE or the GATA site results in both atrial and ventricular ANP transcription in Xenopus (Small and Krieg 2003; 2004). Durocher et al. (1996) have also shown that mutation of NKE in the rat ANP promoter results in upregulation of ANP promoter activity in ventricular cells. These results suggest that the GATA and NKE sites serve as recognition sequences for a repressor complex that inhibits ANP expression in the ventricular myocardium. In this model, the NKE would initially serve as a binding site for the positive transcription factor Nkx-2.5. At the time of atrial restriction of ANP promoter activity, the negative regulatory protein would displace Nkx-2.5 from the NKE and inhibit transcription in the ventricle. There are also other atrial-specific genes, for instance connexin 40 and sarcolipin, having NKE elements in their gene promoters. It is possible that these elements also function as recognition sequences for a ventricular-specific repressor (Small and Krieg 2003; 2004). In the case of the $\mathrm{SCP}$ promoter, the addition of the proximal promoter element from rat BNP gene was capable of activating the $\mathrm{sCP}$ promoter $(-846 \mathrm{sCP} /-134 \mathrm{rBNPluc})$ in ventricular cardiomyocytes, even though two intact NKE elements conforming to the high-affinity $n k x-$ 2.5 consensus binding requirements (Chen and Schwartz, 1995) were present at positions 118 to -124 and -170 to -176 . Thus in this setting NKE does not seem to work with GATA to repress the promoter activity in ventricular cells.

In summary, our results show that the otherwise atrial-specific $\mathrm{sCP}$ promoter can be switched on in rat ventricular cardiomyocytes by adding a short BNP proximal promoter element to the promoter. The placement of the element relative to the transcription start site is crucial; the BNP as a proximal part (nearest to +1 ) brings the highest activity, and it is partly dependent on the -80/-91 GATA sites in the BNP promoter. Thus, the prototypical A-type natriuretic peptide regulation can be transformed to B-type regulation by an insertion of a small exogenous promoter fragment, arguing against a major role of repressors for maintaining the low level expression of A-type natriuretic peptides in ventricular cardiomyocytes. 


\section{REFERENCES}

Barth, A.S., Merk, S., Arnoldi, E., Zwermann, L., Kloos, P., Gebauer, M., Steinmeyer, K., Bleich, M., Kääb, S., Pfeufer, A., Uberfuhr, P., Dugas, M., Steinbeck, G., Nabauer, M., 2005. Pflugers. Arch. 450, 201-208.

Chen, C.Y., Schwartz, R.J., 1995. Identification of novel DNA binding targets and regulatory domains of a murine tinman homeodomain factor, nkx-2.5. Chen CY, Schwartz RJ. J. Biol. Chem. 270, 15628-15633.

Durocher, D., Chen, C.Y., Ardati, A., Schwartz, R.J., Nemer, M., 1996. The atrial natriuretic factor promoter is a downstream target for Nkx-2.5 in the myocardium. Mol. Cell. Biol. 16, 4648-4655.

Durocher, D., Nemer, M., 1998. Combinatorial interactions regulating cardiac transcription. Dev. Genet. 22, 250-262.

Gerbes, A.L., Dagnino, L., Nguyen, T., Nemer, M., 1994. Transcription of brain natriuretic peptide and atrial natriuretic peptide genes in human tissues. J. Clin. Endocrinol. Metab. 78, 1307-1311.

Habets, P.E., Moorman, A.F., Clout, D.E., van Roon, M.A., Lingbeek, M., van Lohuizen, M., Campione, M., Christoffels, V.M., 2002. Cooperative action of Tbx2 and Nkx2.5 inhibits ANF expression in the atrioventricular canal: implications for cardiac chamber formation. Genes Dev. 16, 1234-1246.

Hautala. N., Tokola, H., Luodonpää, M., Puhakka, J., Romppanen, H., Vuolteenaho, O., Ruskoaho, H., 2001. Pressure overload increases GATA4 binding activity via endothelin-1. Circulation 103, 730-735.

Kass-Eisler, A., Leinwand, L.A., 1997. DNA- and adenovirus-mediated gene transfer into cardiac muscle. Methods Cell. Biol. 52, 423-437.

Kokkonen, K., Vierimaa, H., Bergström, S., Tervonen, V., Arjamaa, O., Ruskoaho, H., Järvilehto, M., Vuolteenaho, O., 2000. Novel salmon cardiac peptide hormone is released from the ventricle by regulated secretory pathway. Am. J. Physiol. Endocrinol. Metab. 278, E285-292.

Lorell, B.H., Carabello, B.A., 2000. Left ventricular hypertrophy: pathogenesis, detection, and prognosis. Circulation 102, 470-479. 
Majalahti, T., Suo-Palosaari, M., Sármán, B., Hautala, N., Pikkarainen, S., Tokola, H., Vuolteenaho, O., Wang, J., Paradis, P., Nemer, M., Ruskoaho, H., 2007. Cardiac BNP gene activation by angiotensin II in vivo. Mol. Cell. Endocrinol. 15, 273, 59-67. Majalahti-Palviainen, T., Hirvinen, M., Tervonen, V., Ilves, M., Ruskoaho, H., Vuolteenaho, O., 2000. Gene structure of a new cardiac peptide hormone: a model for heart-specific gene expression. Endocrinology 141, 731-740.

Marttila, M., Hautala, N., Paradis, P., Toth, M., Vuolteenaho, O., Nemer, M., Ruskoaho, H., 2001. GATA4 mediates activation of the B-type natriuretic peptide gene expression in response to hemodynamic stress. Endocrinology 142, 4693-4700.

McBride, K., Nemer, M., 2001. Regulation of the ANF and BNP promoters by GATA factors: lessons learned for cardiac transcription. Can J Physiol Pharmacol. 79, 673-681. McGrath, M.F., de Bold, M.L., de Bold, A.J., 2005. The endocrine function of the heart. Trends Endocrinol. Metab. 16, 469-477.

Pikkarainen, S., Kerkelä, R., Pöntinen, J., Majalahti-Palviainen, T., Tokola, H., Eskelinen, S., Vuolteenaho, O., Ruskoaho, H., 2002. Decoy oligonucleotide characterization of GATA-4 transcription factor in hypertrophic agonist induced responses of cardiac myocytes. J. Mol. Med. 80, 51-60.

Pikkarainen, S., Tokola, H., Kerkelä, R., Majalahti-Palviainen, T., Vuolteenaho, O., Ruskoaho, H., 2003a. Endothelin-1-specific activation of B-type natriuretic peptide gene via p38 mitogen-activated protein kinase and nuclear ETS factors. J. Biol. Chem. 278, 3969-3975.

Pikkarainen, S., Tokola, H., Majalahti-Palviainen, T., Kerkelä, R., Hautala, N., Bhalla, S. S., Charron, F., Nemer, M., Vuolteenaho, O., Ruskoaho, H., 2003b. GATA-4 is a nuclear mediator of mechanical stretch-activated hypertrophic program. J. Biol. Chem. 278, 23807-23816.

Pikkarainen, S., Tokola, H., Kerkelä, R., Ruskoaho, H., 2004. GATA transcription factors in the developing and adult heart. Cardiovasc. Res. 63, 196-207.

Ross, R.S., Navankasattusas, S., Harvey, R.P., Chien, K.R., 1996. An HF-1a/HF-1b/MEF-2 combinatorial element confers cardiac ventricular specificity and established an anterior-posterior gradient of expression. Development 122, 1799-1809.

Ruskoaho, H., 1992. Atrial natriuretic peptide: synthesis, release, and metabolism. Pharmacol. Rev 44, 479-602. 
Small, E.M., Krieg P.A., 2003. Transgenic analysis of the atrialnatriuretic factor (ANF) promoter: Nkx2-5 and GATA-4 binding sites are required for atrial specific expression of ANF. Dev Biol 261, 116-131.

Small, E.M., Krieg, P.A., 2004, Molecular regulation of cardiac chamber-specific gene expression. Trends. Cardiovasc. Med. 14, 13-18.

Suo, M., Hautala, N., Földes, G., Szokodi, I., Toth, M., Leskinen, H., Uusimaa, P., Vuolteenaho, O., Nemer, M., Ruskoaho, H., 2002. Posttranscriptional control of BNP gene expression in angiotensin II-induced hypertension. Hypertension 39, 803-808.

Tabibiazar, R., Wagner, R.A., Liao, A., Quertermous, T., 2003. Transcriptional profiling of the heart reveals chamber-specific gene expression patterns. Circ. Res. 93, 1193-1201.

Temsah R, Nemer M., 2005. GATA factors and transcriptional regulation of cardiac natriuretic peptide genes. Regul. Pept. 128, 177-185.

Tervonen, V., Arjamaa, O., Kokkonen, K., Ruskoaho, H., Vuolteenaho, O., 1998. A novel cardiac hormone related to A-, B- and C-type natriuretic peptides. Endocrinology 139, 4021-4025.

Tervonen, V., Kokkonen, K., Vierimaa, H., Ruskoaho, H., Vuolteenaho, O., 2001. Temperature has a major influence on cardiac natriuretic peptide in salmon. J. Physiol. 536, 199-209.

Tervonen, V., Ruskoaho, H., Vuolteenaho, O., 2000. Novel cardiac peptide hormone in several teleosts. J. Endocrinol. 166, 407-418.

Tervonen, V., Ruskoaho, H., Lecklin, T., Ilves, M., Vuolteenaho, O., 2002. Salmon cardiac natriuretic peptide is a volume-regulating hormone. Am. J. Physiol. Endocrinol. Metab. 283, E353-361.

Vierimaa, H., Hirvinen, M., Tervonen, V., Arjamaa, O., Ruskoaho, H., Vuolteenaho, O., 2002. Pronatriuretic peptide is a sensitive marker of the endocrine function of teleost heart. Am. J. Physiol. Endocrinol. Metab. 282, E843-850.

Vierimaa, H., Ronkainen, J., Ruskoaho, H., Vuolteenaho, O., 2006. Synergistic activation of salmon cardiac function by endothelin and beta-adrenergic stimulation. Am. J. Physiol. Heart Circ. Physiol. 291, H1360-1370. 


\section{Acknowledgments}

Supported by grants from the Finnish Cultural Foundation, the Emil Aaltonen Foundation, the Finnish Foundation for Cardiovascular Research, Oulu University Scholarship Foundation, Aarne and Aili Turunen Foundation, Ida Montin Foundation, Oulu University Pharmacy Fund and the Sigrid Juselius Foundation. 


\section{FIGURE LEGENDS}

Figure 1. Assembly and structure of the promoter constructs employed in the present study.

Figure 2. A, Basal promoter activity of the native hybrid sCP constructs. The $\mathrm{sCP} / \mathrm{BNP}$ hybrid promoter constructs were transfected to ventricular cardiomyocytes and the basal promoter activities were compared to -1686 sCPluc. The results (mean $\pm \mathrm{SD}, \underline{n}=10-12$ ) are expressed as relative luciferase units corrected by the renilla luciferase activity. $* * * \underline{P}<0.001$ compared to -1686 sCPluc; $\# \# \underline{P}<0.01$, difference between the activities of the intact and mutated promoters. B, Activity of the sCP promoter construct [sCPgapluc ( -1426/-957/-96 sCPluc)] in which the GATA-, CArG- and AP-1 -rich sequences have been moved closer to the transcription start site. The results (mean $\pm \mathrm{SD}, \underline{n}=10$ ) are expressed as relative luciferase units corrected by the renilla luciferase activity. ${ }^{* * *} \underline{P}<0.001$ compared to -1686 sCPluc. The experiments were repeated three times with similar results.

Figure 3. Gel mobility shift assay with neonatal rat ventricular cardiomyocyte nuclear extracts using sCP GATA -1417 probe (lanes 1-7) or sCP GATA(-) -148 probe (lanes 8-14). Binding to the sCP probes were competed with 50-fold molar excess of cold sCP probes (lanes 3 and 10). The specificity of the GATA binding was determined by supershift assays by incubating the nuclear extracts with anti-GATA-4 (lanes 4, 11), anti-GATA-5 (lanes 5, 12), anti-GATA-6 (lanes 6,13) or anti-Oct-1 (lanes 7, 14). The experiments were repeated two times with similar results.

Figure 4. Activity of constructs in which small GATA and EBS binding sites are from rBNP proximal promoter are inserted to the 5 'site of the $\mathrm{SCP}$ promoter. The basal activity of the oligonucleotide GATA and EBS (intact/mutated) BNP/-96 sCP hybrid promoters are compared to $-96 \mathrm{sCPluc}$ in neonatal rat ventricular cells. The results (mean $\pm \mathrm{SD}, \underline{n}=4-12)$ are expressed as relative luciferase units corrected by the renilla luciferase activity. ${ }^{* * *} P<0.001$ compared to -96 sCPluc; \#\#\# $\underline{P}<0.001$, difference between the activities of the intact and mutated promoters. The experiments were repeated three times with similar results. 
Figure 5. Effect of mechanical stretch on the promoter activity. Transfected myocytes were stretched cyclically up to $24 \mathrm{~h}$ ( $105 \%$ amplitude in 2 -s cycles). The results (mean $\pm \mathrm{SD}, n=4$ ) are expressed as relative luciferase units corrected by the renilla luciferase activity. ${ }^{*} P<0.05$ compared to non-stretched control. The experiments were repeated two times with similar results.

Figure 6. Effect of endothelin-1 on the promoter activity. $10 \mathrm{nM} \mathrm{ET-1}$ was added for 24 hours to the growth medium of the transfected neonatal rat ventricular myocytes. The results $($ mean $\pm \mathrm{SD}, \underline{n}=4-5)$ are expressed as relative luciferase units corrected by the renilla luciferase activity. $* * * \underline{P}<0.001$ compared to vehicle-treated control. The experiments were repeated three times with similar results.

Figure 7. Basal and angiotensin II-induced activity of the promoters in in rat left ventricle in vivo. The $-534 \mathrm{rBNPluc}$ and $-1686 \mathrm{sCPluc}$ constructs were injected into the myocardium of rat left ventricle. Ang II $33.3 \mu \mathrm{g} / \mathrm{kg} / \mathrm{h}(31.5 \mathrm{nmol} / \mathrm{kg} / \mathrm{h})$ or $0.9 \% \mathrm{NaCl}$ were administered by subcutaneous osmotic minipumps for 2 weeks in conscious rats. The animals were then sacrificed and left ventricular samples from the injection area were collected and assayed for promoter activity. Luciferase values were divided by $\beta$-galactosidase values to correct for variation in transfection efficiency. The results are expressed as mean $\pm \mathrm{SD}, \underline{n}=5-6) . * * \underline{P}<0.01$ compared to vehicle-treated control. The experiments were repeated two times with similar results. 


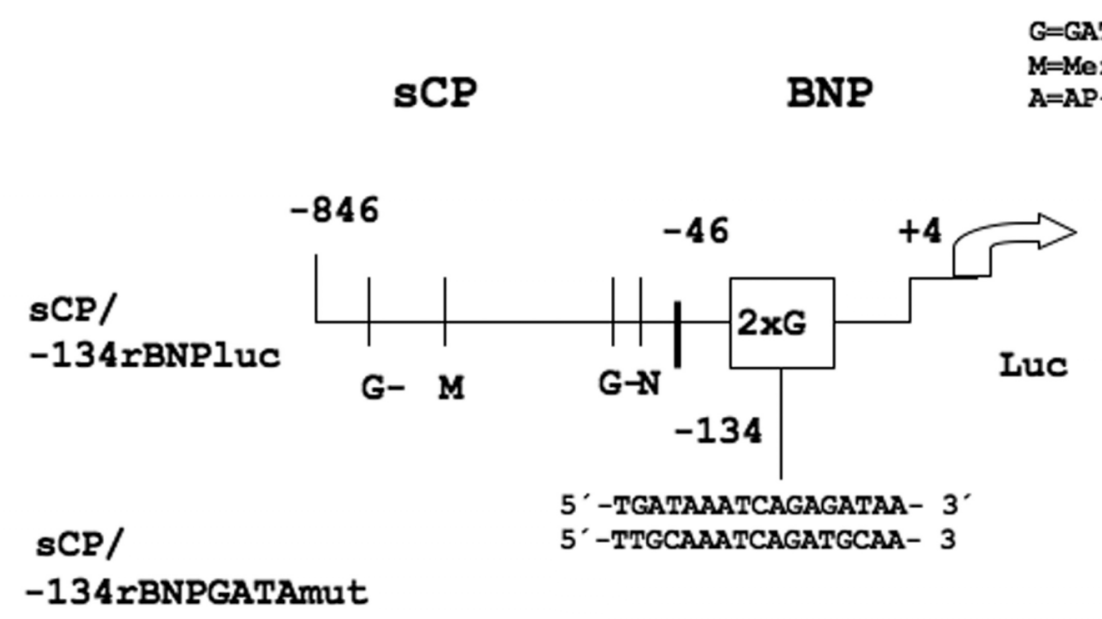

sCP
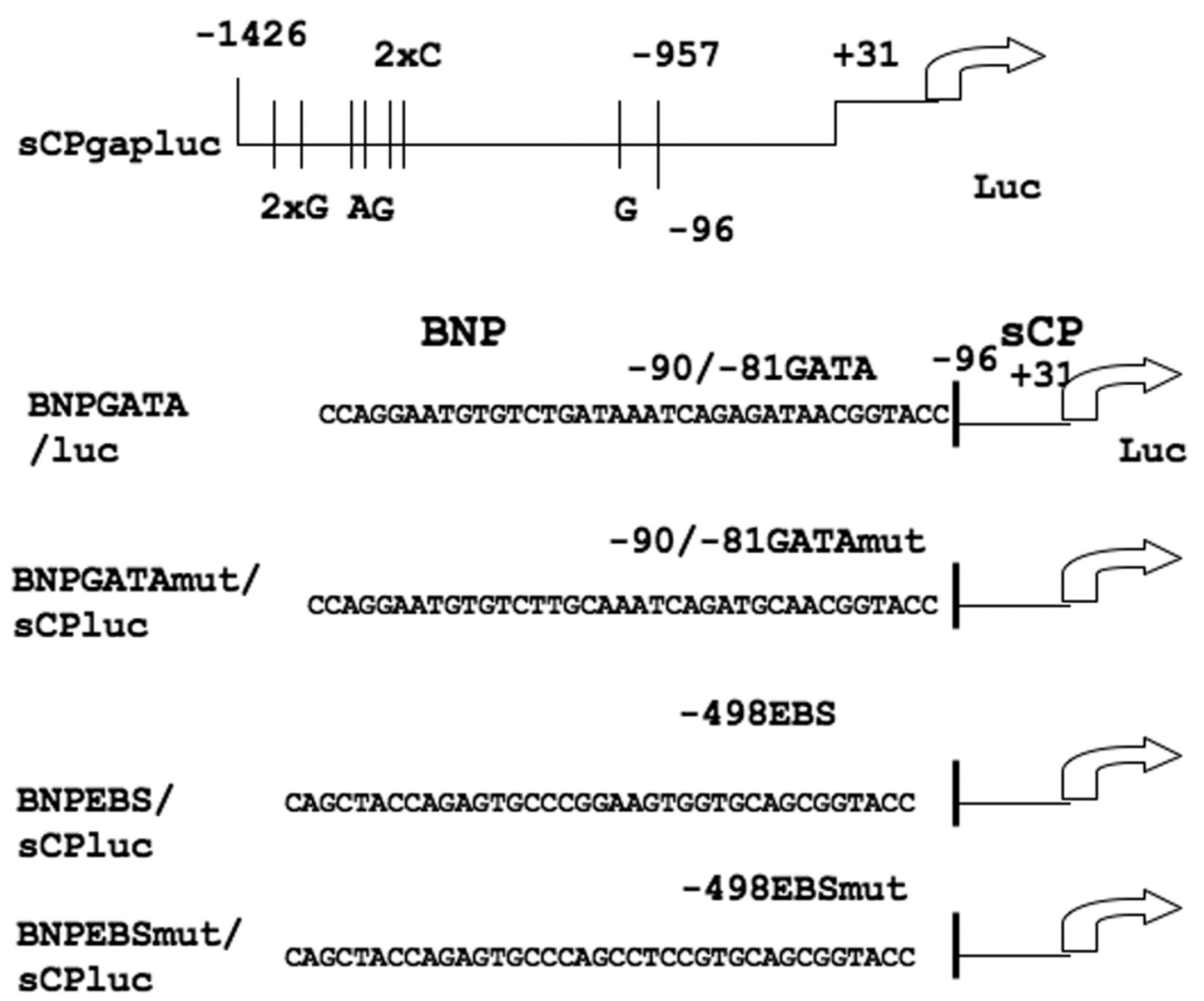

Figure 1 

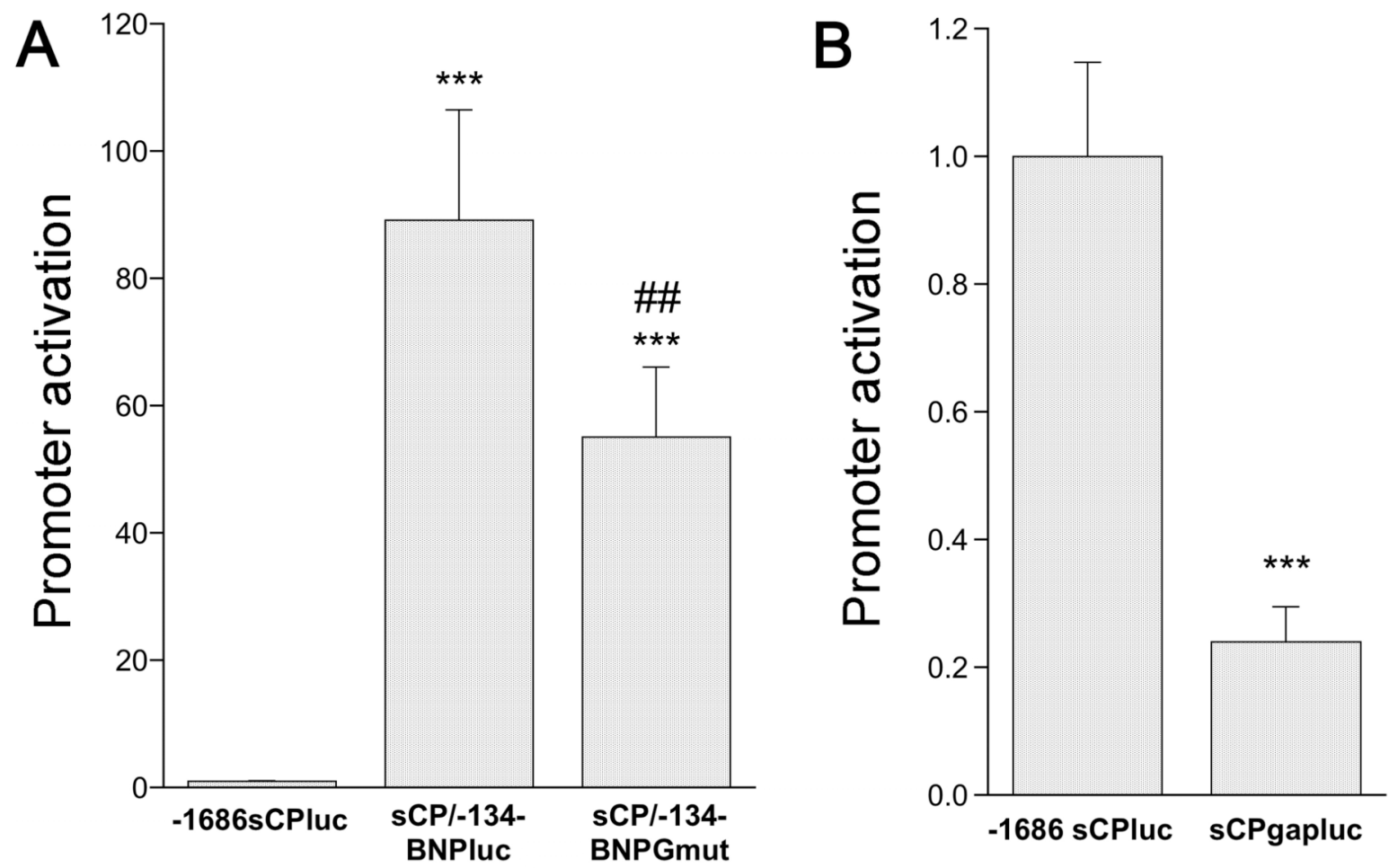

Figure 2. 


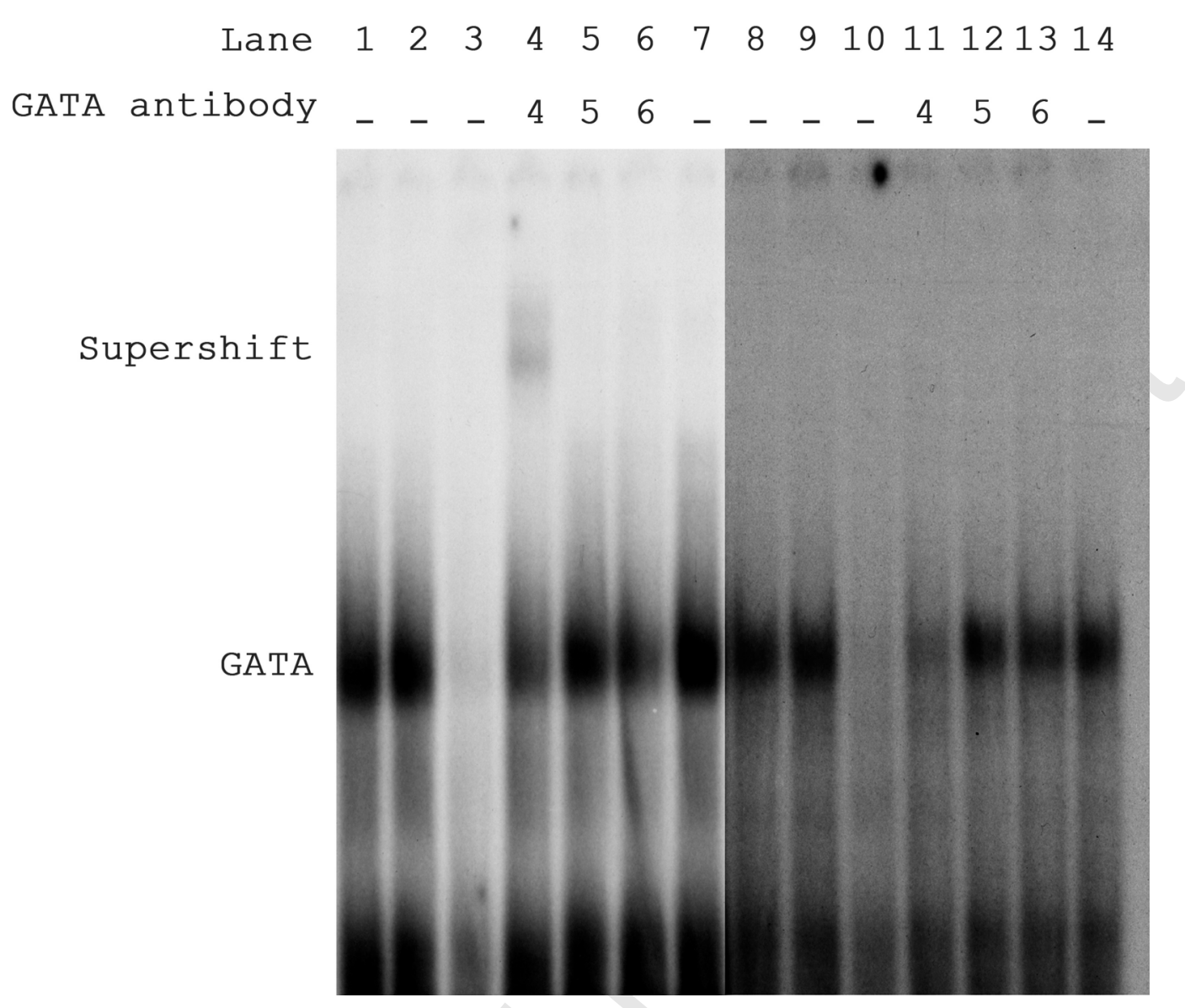

Figure 3. 


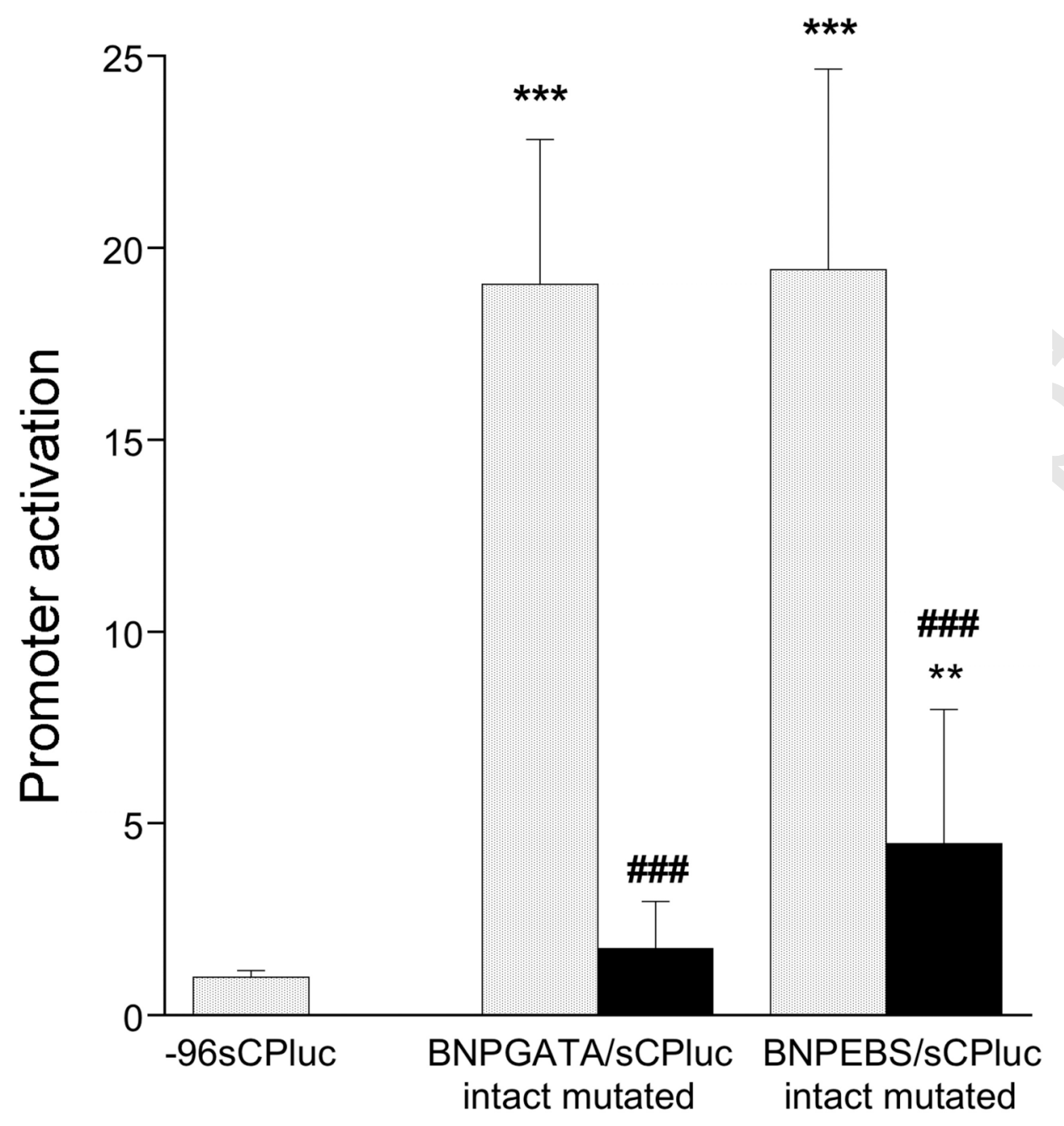

Figure 4. 


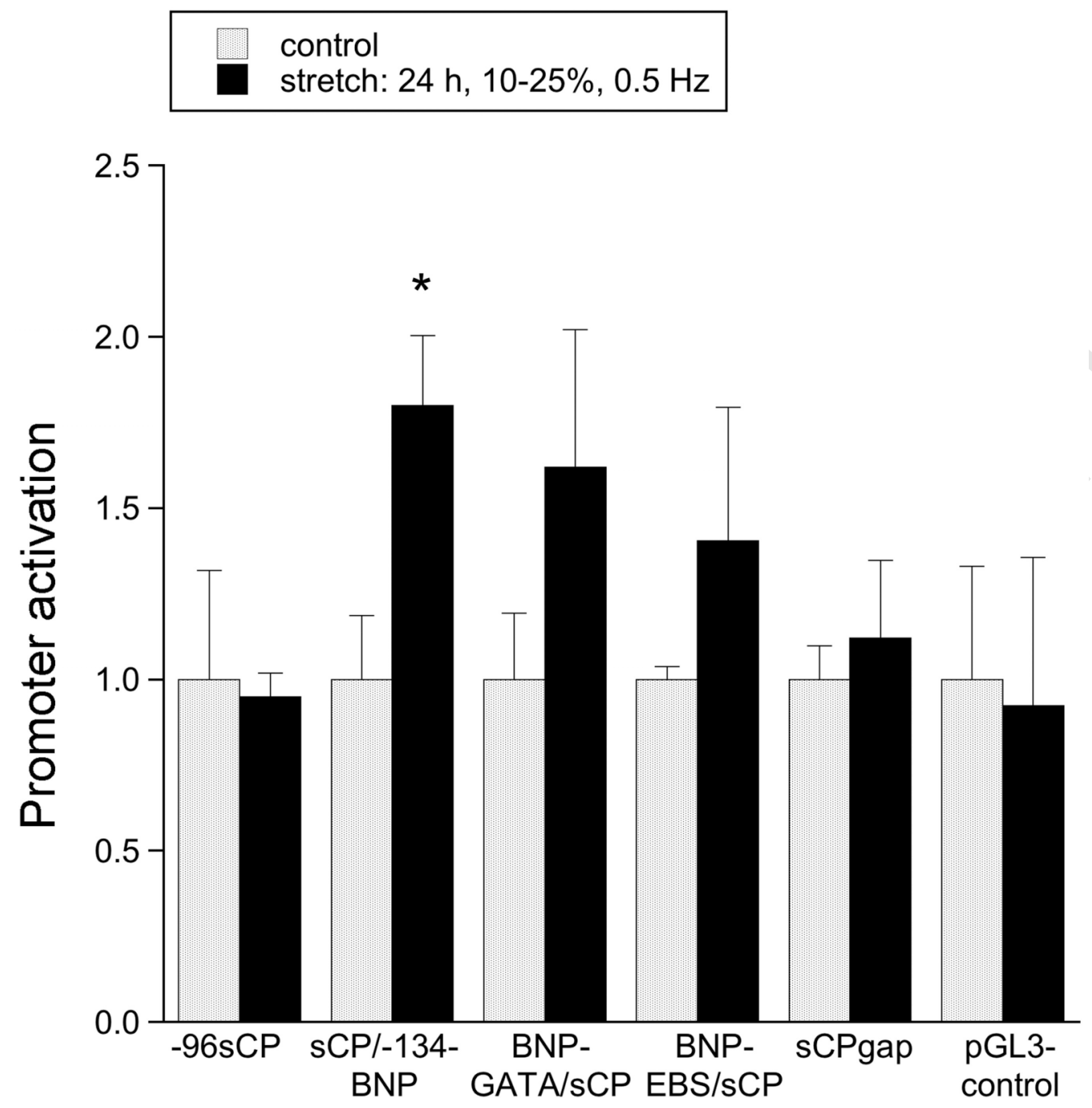

Figure 5. 


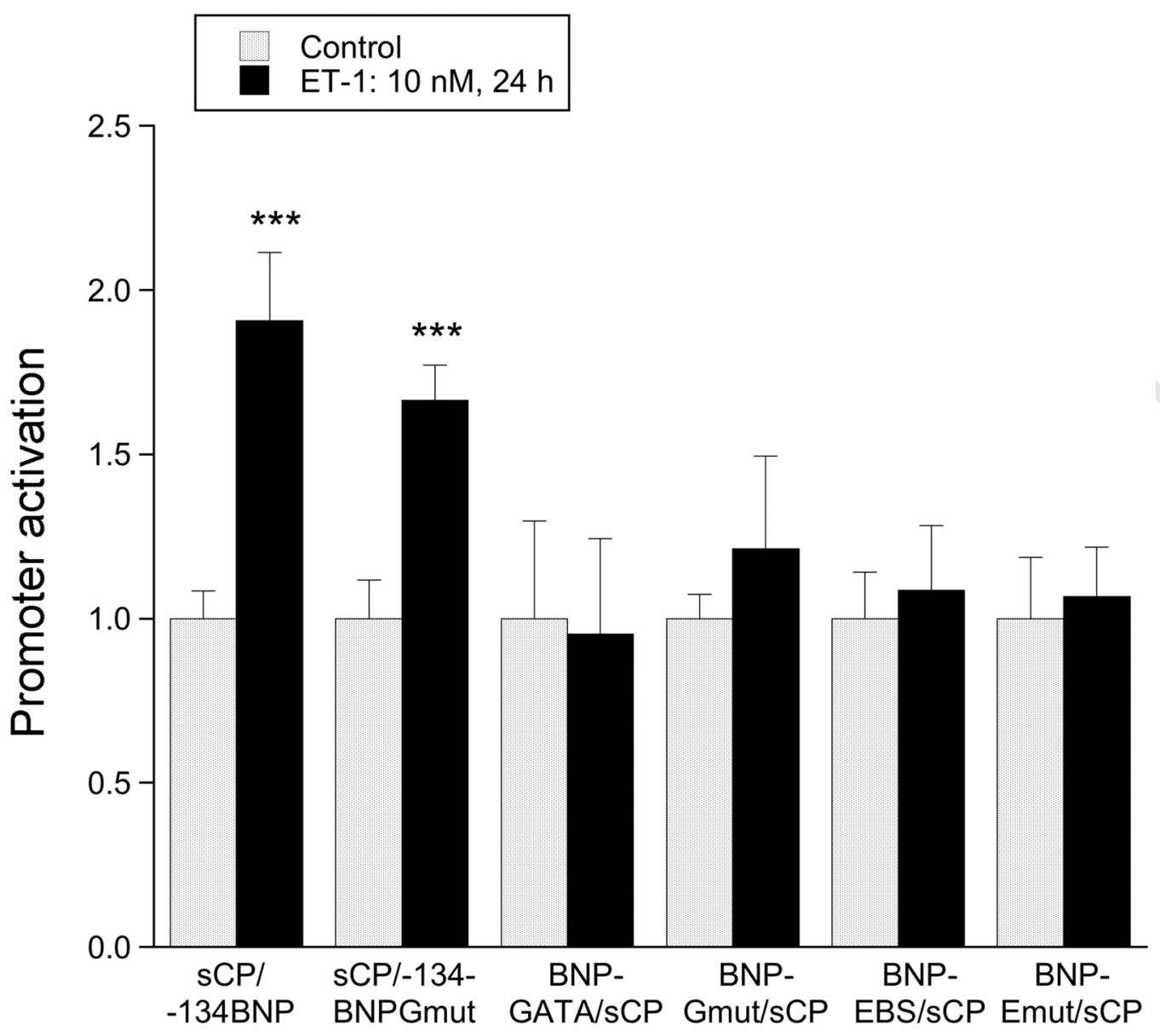

Figure 6. 


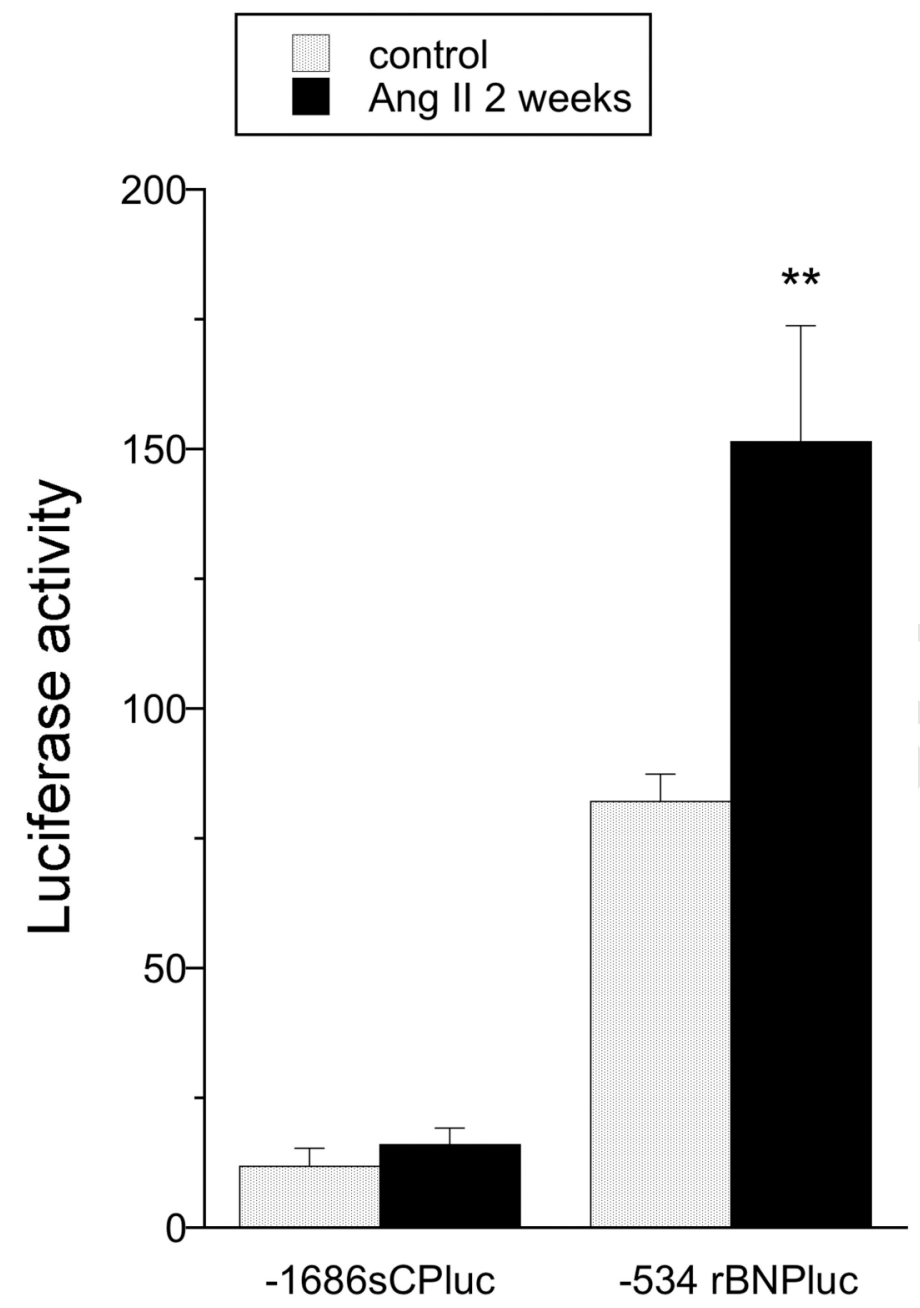

Figure 7. 